\title{
Keeping the door open: Exploring experiences of, and responses to, university students who disclose mental illness
}

\author{
Donna McAuliffe \\ Griffith University \\ Jennifer Boddy \\ Griffith University \\ Vanette McLennan \\ Griffith University \\ Victoria Stewart \\ Griffith University
}

\begin{abstract}
University educators increasingly manage situations where students disclose serious mental health issues. This is a significant issue, particularly for health and human service professions, as the importance of valuing the lived experience of mental illness lies alongside concerns for professional practice standards. Thus the responsibilities of students to disclose their mental health status and the responsibilities of Universities to provide appropriate support within established disability frameworks must be clear. However, students often do not know who they should disclose to, what will happen to disclosed information, and who has access to this information. Student's often fear embarrassment, stigma, and shame about disclosing mental illness, which is compounded by the diverse attitudes, experiences, and beliefs of educators. Consequently, this paper will review existing literature on university responses to, and students' experiences of, mental illness in order to set a research agenda for this topic. The authors argue that such research must be undertaken urgently, in a context of inclusivity in higher education that gives voice to the experiences of students, their families and carers, university staff, and practitioners in the field.
\end{abstract}

Keywords: Mental illness; mental health; tertiary education; disclosure; inclusion; professional standards 


\section{Introduction}

The mental health of $18-25$ year old Australians is an increasing concern. Recent studies indicate that this age group is at significantly higher risk of mental illness, with three quarters of all Australians experiencing mental illness having their first episode by the age of 25 (Australian Bureau of Statistics, 2007). Although underreported, suicide is one of the most common causes of death for this age group (Australian Institute of Health and Welfare, 2010). This age group also represents the majority of tertiary education students, where pressures and demands can be unexpectedly high and burdensome. Perhaps somewhat unsurprising then are recent findings indicating a higher prevalence of mental illness and psychological distress among university students than in the general population (see Bayram \& Bilgel, 2008; Cleary, Horsfall, Baines, \& Happell, 2011; Hunt \& Eisenberg, 2010; Shankar, Martin, \& McDonald, 2009; Stallman, 2008). This has led, in part, to the authors questioning the adequacy of universities' response to, and support of, students with mental illness and indeed their recognition of a duty of care in relation to mental illness and suicide prevention. Further validation for an interest in this area was invitation to attend the National Summit on the Mental Health of Tertiary students held in August 2011, with a number of prominent speakers discussing policy and practice responses to this area of need (see www.cshe.unimelb.edu.au/nationalsummit/).

As well as being a time of increasing psychological distress for people of this age group, formal education and training is often understandably disrupted or truncated. Mental illness can impede school-to-work transitions and damage the early stages of career path formation and the acquisition of work values, work ethics, and core work skills (Kessler, Foster, Saunders, \& Stang, 1995; Lloyd \& Waghorn, 2007; Waghorn, Still, Chant, \& Whiteford, 2004). Research has shown that many individuals who experience mental health difficulties and psychiatric disability want to pursue postsecondary education (Mansbach-Kleinfeld, Sasson, Shvarts, \& Grinshpoon, 2007; Martin \& Oswin, 2007; Shankar et al., 2009), which can have a positive effect on mental health and wellbeing for some (Toombs \& Gorman, 2011) and is considered to have good psychosocial rehabilitation outcomes when people are fully supported (Mowbray et al., 2005; Wolf, Coba, \& Cirella, 2001). In an exploration of the meaning of education for university students with a psychiatric illness, Wiener (1999) found the university experience to be founded on an education/recovery continuum with the meaning of education being about normalisation, structure and hope. National mental health strategies build on this platform of understanding by encouraging people with mental illness into employment, which University education is a pathway to (Stanley, Manthorpe, \& White, 2007; Waghorn et al., 2004). Postsecondary education has the potential to help people with mental illness be more competitive in the labour market and enhance employment opportunities. However, without specialised educational interventions, a substantial proportion of persons with psychosis and other mental health conditions will experience lifelong educational and economic disadvantage. 
The authors of this article have increasingly managed situations where students disclose often quite serious mental health issues, either at the time of entering a program of study, or around the time of preparing for field placement which is often a requirement of many professional disciplines. These experiences have resulted in much discussion about internal processes for supporting these students, and have highlighted the difficulty of doing this adequately both in the distance and on-campus education environments. While these are not new discussions, and similar issues have been raised in literature over the past decade (see Collins, 2006; Manthorpe \& Stanley, 1999; Owen \& Rodolfa, 2009; Shaddock, 2004), there is a dearth of literature on student experiences of disclosure of mental health status across health and human services in Australia. Only four studies were located in Australian university. One related to supervision of university students with a physical disability (Cooley \& Salvaggio, 2002), two to nursing students mental health problems and transition to university (Cleary, Horsfall, et al., 2011; Cleary, Walter, \& Jackson, 2011), and another looking at Indigenous students mental health and wellbeing (Toombs \& Gorman, 2011). This is problematic, and suggests urgent research in the area is needed, including on the experience of students with mental illness at university and the most effective strategies to better support students through to graduation and into the workforce.

\section{Student experiences}

\section{Stigma, discrimination and disclosure}

The decision for students to disclose a mental illness is a sensitive one, and can be influenced by both the fear of stigma and discrimination and the need for reasonable accommodations and special consideration. A major study conducted in the United Kingdom by the Social Care Workforce Research Unit (Ridley, Stanley, Manthorpe, \& Harris, 2008; Stanley, Ridley, Manthorpe, Harris, \& Hurst, 2010) found that professionals and students who disclosed their mental health status in nursing, teaching, and social work did not know who they should disclose to, what would happen to disclosed information, and who had access to this information. In medicine, students associated significant stigma with help-seeking behaviour and cited widespread avoidance of disclosure of problems (Chew-Graham, Rogers, \& Yassin, 2003). Students who do disclose a disability, whether apparent or hidden, generally do this purposefully and carefully, and the extent of disclosure relies on the nature of the relationship with the staff member (Olney \& Brockelman, 2003). According to Wiener (1996), this is because students experience a fear of embarrassment and shame about disclosing personal details, particularly at the beginning of their educational experience. In a study of Australian TAFE students, the availability of support services and anti-discrimination legislation were not sufficient motivators for disclosure, even when students were repeatedly encouraged to disclose mental illness (Venville, 2010). Nonetheless, the need for good relationships and a culture of support between staff and students is a prerequisite for disclosure (Furness \& Gilligan, 2004). Further, a culture of inclusivity for students who have disabilities is needed so that constructive differences rather than 
problems can be the focus of policies (Crawshaw, 2002; Megivern, Pellerito, \& Mowbray, 2003).

\section{Help-seeking behaviour}

An alarmingly common theme in the research is the reluctance of young university students with mental health concerns to engage in help-seeking behaviours. This is particularly concerning considering recent research conducted by Stanley, Mallon, Bell, and Manthorpe (2010) found that failure to engage with support services could have been a primary factor in completed suicides of students in higher education. This lack of student engagement was apparent in a large survey of college students in the United States, where $67 \%$ perceived a need for mental health services but only $38 \%$ had sought such services in the preceding year (Cranford, Eisenberg, \& Serras, 2009). The fact that mental health concerns of this population are often not matched with helpseeking and service use has been mentioned by several authors (see Hunt \& Eisenberg, 2010; McMichael \& Hetzel, 1974; Stallman, 2008; Toombs \& Gorman, 2011; Zivin, Eisenberg, Gollust, \& Golberstein, 2009) and suggests there are likely significant unmet needs for treatment of mental illness among university students. However, it is unknown whether students fail to engage in help-seeking behaviours due to their own reluctance or fear, which may be associated with real or perceived stigma, or due to a lack of available or suitable mental health services, or both. Interestingly, and a potential solution to issues of accessibility of mental health services, is the finding of an Australian study of an online intervention for promoting wellbeing in university students. Ryan, Shochet, and Stallman (2010) found that while students were less likely to seek services in times of escalating psychological distress, their intention to use online mental health interventions increased. This could have important implications for university support services wishing to improve their response to the mental health concerns of students.

\section{Academic and field educator attitudes}

Academics are often unsure how to respond to student disclosure of mental illness, and this can lead to inconsistent provisions of support for students who have made the difficult decision to disclose. Inconsistencies in academic attitude and response may be the result of factors operating at an institutional level and a personal level. Studies have identified several issues of concern for academics, including the need for clearer procedures and policies, in line with legislation, as reported by social work field educators in a study focussed on supervision of students with psychiatric disability (Gillis \& Lewis, 2004). A survey of social work educators by Glenmaye and Bolin (2007) indicated the presence of varying attitudes regarding psychiatric disability in social work education and in the profession, along with differing rates of the availability of psychiatric disability policies and accommodations (indeed only 33\% reported their department had a psychiatric disability policy). Academics in the study expressed academic, practicum, and social concerns regarding students with mental illness. More broadly in the higher education sector, university staff have reported feeling frightened and unprotected by 
their employing university in response to the behaviour of some students with mental illness, and expressed uncertainty about the treatment of students with mental illness, including diverse attitudes to special consideration, with only $67 \%$ believing students with mental illness should be granted special consideration (Shaddock, 2004). These findings in academic attitudes and responses are possibly the result of a lack of clear policies and procedures for psychiatric disability in education and/or a lack of understanding of disability discrimination legislation and its implications for legal responsibilities in the provision of 'reasonable accommodations' for students with disabilities, be them physical or psychological in nature.

The issue of inconsistent attitudes and responses to students with mental illness may be somewhat compounded by the influence of academics' personal experience and level of empathy. Research has found that academics who have had personal experience with psychiatric disability are more likely to be supportive and positive in working with students who disclose mental illness (Brockelman, Chadsey, \& Loeb, 2006). Increasing the awareness and understanding of mental illness across universities could promote such a positive and supportive response.

\section{University responses}

\section{Treatment and interventions}

Strategies and interventions to address the concerning prevalence of mental illness in university students have been widely discussed, and universities have a clear responsibility to adopt evidence-based support services to promote the mental health and wellbeing of students and, in turn, encourage their academic success. Stanley, Mallon, Bell, and Manthorpe (2010) highlighted the need for specialist mental health advisors within Universities to link more strategically with general practitioners and primary care providers. Open communication and collaboration between students and staff, and the availability of enhanced mental health services, is considered key to preventing worsening psychopathology of students and improving student retention (Schwartz \& Kay, 2009). Improving on-campus mental health services and programs and ensuring early intervention and individualised support has also been emphasised (Shaddock, 2004). This could entail the co-location of specialist mental health services, including a general practitioner, psychiatrist, and psychologist, aimed at increasing availability of services and ensuring a more comprehensive response to the mental health concerns of students (Stallman, 2008).

Studies have also investigated on-campus intervention projects, which have shown promising outcomes in promoting mental health and wellbeing of students. One such project, which implemented peer-based suicide prevention and mental health training for students in an Australian university, found preliminary improvements in students' attitudes, self-efficacy, social connectedness and mental health literacy as well as intentions toward talking with fellow students about mental health problems (Pearce, Rickwood, \& Beaton, 2003). Studies have proposed several strategies to promote the mental health of students, including programs to increase student self-determination 
(Brockelman, 2009), optimism and health values (Burris, Brechting, Salsman, \& Carlson, 2009), and provide a standardised well researched cognitive-behavioural approach (Buchanan, 2011) which aims to reduce psychological distress by improving student coping strategies (Khawaja \& Dempsey, 2007). Online mental health interventions have also been examined, and the provision of these may go some way in addressing the low rate of help seeking among 18-25year olds. They offer assistance to those who would otherwise not seek formal help (Ryan et al., 2010), and to those who prefer to solve their personal problems online for reasons of convenience or to reduce feelings of vulnerability (Piper \& MacDonald, 2008).

Models of supported education for people with psychiatric illness provide an important opportunity for people with mental illness to be self-determining and realise their educational and employment goals, and have been discussed predominantly in the United States. Supported education programs, which come under a psychosocial rehabilitation model entail support, reassurance, and encouragement, and have been shown to assist students with psychiatric disabilities to engage in, and complete, tertiary education (Mowbray et al., 2005). The inclusion of strategies to increase student empowerment, social and interpersonal competence, and communication skills within a supported education model promote recovery through the attainment of formal education and employment in the behavioural health field (Wolf et al., 2001). The psychosocial rehabilitation and supported education models reflect the social justice and ethical foundations of the health and human service professions and utilising these in their education programs may help to improve opportunities for mental health service users.

A whole-of-university approach, proposed by Owen and Radolfa (2009), calls for universities to actively engage in the development and improvement of student mental health services to create a "campus that cares" culture. This will require the adoption of innovative strategies to increase protective factors, such as social support and awareness, and decrease risk factors, such as alcohol use and depression (Owen, Tao, \& Rodolfa, 2006). Through the provision of counselling centres, improved collaboration and communication between all stakeholders, clear plans of response to student distress, and more welcoming attitudes and physical spaces on campus, a comprehensive university-wide approach would promote mental health by improving campus culture, interpersonal relationships, and intrapersonal functioning (Owen \& Rodolfa, 2009).

\section{Fitness to practice}

There is a body of literature, predominantly from the United States, that focuses on the links between personal history and professional impairment. The literature reveals that concerns about students with mental illness has become aligned with assessments of 'fitness to practice', which often has negative connotations with its focus on deficits and problems. Literature has also focussed on the necessity of delineating what is meant by 'suitability, unsuitability, or misconduct' when universities try to enforce what has become termed 'gatekeeper responsibilities' (Currer, 2009; Dillon, 2007; Lafrance \& 
Gray, 2004). In the UK, much research has explored the regulatory frameworks for students with disabilities, including psychiatric disabilities, and there is an expectation amongst university teaching staff that students should disclose disabilities that could impact on practice or academic performance (Currer, 2009; Sin \& Fong, 2009; Wray, Gibson, \& Aspland, 2007). This is in the interests of ensuring that service users are not harmed, and that the reputation of professions is upheld. Yet, many students with mental illness are likely to be treated more negatively within regulatory systems than students with physical disabilities (Sin \& Fong, 2009).

Authors argue that students or practitioners who experience personal difficulties should not face punishment or stigmatisation in the process of universities or workplaces attempting to address these difficulties (see Pooler, Clay Siebert, Faul, \& Huber, 2008). Instead, an empowerment model would see the positive benefits of shared experience within the philosophy that recovery is possible and that symptoms can be managed (Stromwall, 2002).

\section{Policy development, dissemination and implementation}

The need for improved, transparent, and accessible policy and procedures is repeatedly discussed throughout the literature on responding to students with mental illness. These policies need to clearly reflect disability discrimination legislation to ensure they are fair (Gillis \& Lewis, 2004). They need to acknowledge the relevance of students' psychiatric illness and help foster their educational success while upholding professional standards (GlenMaye \& Bolin, 2007). Shaddock (2004) called for policy development to be matched with staff training and increased awareness of the disability discrimination act, a strategy aimed at not only improving the response to known students with mental illness, but also at encouraging disclosure by reducing stigma through increased mental health literacy. Further, the dissemination of information on rights, responsibilities, and implications in relation to disclosing mental illness, would encourage understanding, improve 'disability friendliness' in the institution, and promote disclosure among students (Ridley et al., 2008).

\section{Developing a Research Agenda for Inclusivity in Higher Education}

It is clear from the literature that there is room for development of a research agenda in Australia that will assist universities in their determinations about how inclusive cultures can be created and sustained. Such research will help universities and educators better respond to students with mental illness.

To date there has been insufficient exploration of how tertiary students with mental illness navigate the services and structures that on the one hand could support and nurture an educational experience, and on the other discriminate against students and disrupt or terminate a potential career pathway. There is no research that gives insight into what prevents students from engaging in help-seeking behaviour when support services are in existence. The views of students themselves need to be explored through qualitative research, so that they can identify through their own reflective lens 
about what helped and what hindered their educational progress, and what services were or were not accessed. From the student perspective, research questions could focus on experiences of stigma, discrimination, and disclosure at both the point of entry into a university and throughout a program of study.

Many students will have engaged in study at different times in their lives and at different levels (for example, Vocational Education and Training sector, undergraduate, postgraduate) and their experiences may have been different depending on the program of study, the mode of study, and the university chosen. Further exploration is warranted as to the differences in attitude and response to students with mental health issues across disciplines and professions. Additionally, what is not known at this point from literature are any differences that arise from decisions about studying in distance or oncampus, and whether distance study does afford students with mental illness more anonymity and therefore a greater sense of security from perceived stigma. It is now possible for a student to complete a full degree online without ever needing to engage face-to-face with a lecturer or any other university staff member. From the student perspective, it would also be useful to know how students perceive their disclosure of information, where this happens, how it has been handled and managed by university staff, and whether they had concerns about the sharing of personal information, records kept on file about their circumstances, and how they understood issues of consent and duty of care. The experiences of families and carers of students with mental illness should also be a focal point of research as part of this agenda.

As previously mentioned, many professional disciplines have requirements that students complete field placements in external agencies with supervision from practitioners in the field. Issues are raised in this context about sharing of information to external third parties, and what rights students have to withhold information from potential field placement agencies, what rights potential field supervisors have to know information about students who will be engaging with clients of that agency, and what responsibilities universities have in their dual relationships with both students and the field. The question is raised here about how universities and the staff employed within these institutions remain responsive to individual needs of students, but also uphold professional standards and their own reputation in consistent management of sensitive issues. Thus, there is need for more investigation in Australia that includes direct information from students with mental illness about their views and experiences. This information can be used to educate field and university educators, as well as administrative staff and those with responsibilities for policy development in the area of student support.

\section{Conclusions}

Ensuring universities respond to students with mental illness in a manner that is not only cognisant of professional standards, but is also inclusive, valuing of the lived experience, respectful, and non-discriminatory is imperative. Given that students who pursue academic programs at university, particularly in disciplines that require field or clinical 
placements, are encouraged to disclose any mental health history that may impact on their ability to provide quality service to others, universities must put in place policies and program responses that do not discriminate on the basis of mental illness and do not place student inclusion in higher education at risk. Research indicates clearly that engagement with higher education can be a positive motivator for mental health for those students who may have had difficulty establishing a career pathway due to mental illness. The other side of the issue is concern for professional practice standards, and assurance that students who experience problems related to mental illness will take all required steps to engage support. There is a lack of research that explores the student experience of disclosure of mental illness, and the associated responses of university staff to such disclosures. This paper argues that there is room for a substantial research agenda to be developed around this complex issue so that these issues can be better understood from a range of perspectives. It is clear that the mental health of tertiary students is on the national agenda for discussion as evidenced by the National Summit held in 2011. These discussions should continue within a context of inclusivity in higher education, and within a research framework that will give voice to the experiences of students, their families and carers, university staff, and practitioners in the field.

\section{References}

Australian Bureau of Statistics. (2007). National Survey of Mental Health and Wellbeing: Summary of Results. ABS Cat No. 4326.0. Canberra: ABS.

Australian Institute of Health and Welfare. (2010). Australia's Health 2010 Australia's health series no. 12. Cat. no. AUS 122. Canberra: AlHW.

Bayram, N., \& Bilgel, N. (2008). The prevalence and socio-demographic correlations of depression, anxiety and stress among a group of university students. Social Psychiatry and Psychiatric Epidemiology, 43, 667-672.

Brockelman, K. F. (2009). The Interrelationship of Self-Determination, Mental Illness, and Grades Among University Students. Journal of College Student Development, 50(3), 271-286. doi: 10.1111/j.1559-1816.2004.tb02690.x

Brockelman, K. F., Chadsey, J. G., \& Loeb, J. W. (2006). Faculty perceptions of university students with psychiatric disabilities. Psychiatric Rehabilitation Journal, 30(1), 23-30.

Buchanan, J. L. (2011). Prevention of Depression in the College Student Population: A Review of the Literature. Archives of Psychiatric Nursing, In press, 1-22.

Burris, J., Brechting, E., Salsman, J., \& Carlson, C. (2009). Factors Associated With the Psychological Well-Being and Distress of University Students. Journal of American College Health, 57(5), 536-543. doi: 10.1080/016128499248709

Chew-Graham, C. A., Rogers, A., \& Yassin, N. (2003). 'I wouldn't want it on my CV or their records': medical students' experiences of help-seeking for mental health problems. Medical education, 37(10), 873-880.

Cleary, M., Horsfall, J., Baines, J., \& Happell, B. (2011). Mental health behaviours among undergraduate nursing students: Issues for consideration. Nurse Education Today, In press. 
Cleary, M., Walter, G., \& Jackson, D. (2011). "Not always smooth sailing": Mental health issues associated with the transition from high school to college. Issues in Mental Health Nursing, 32(4), 250-254. doi: 10.3109/01612840.2010.548906

Collins, S. (2006). Mental Health Difficulties and the Support Needs of Social Work Students: Dilemmas, Tensions and Contradictions. Social Work Education, 25(5), 446-460.

Cooley, B., \& Salvaggio, R. (2002). Ditching the 'dis' in disability: Supervising students who have a disability. Australian Social Work, 55(1), 50-59.

Cranford, J. A., Eisenberg, D., \& Serras, A. M. (2009). Substance use behaviors, mental health problems, and use of mental health services in a probability sample of college students. Addictive Behaviors, 34, 134-145.

Crawshaw, M. (2002). Disabled people's access to social work education: Ways and means of promoting environmental change. Social Work Education, 21(5), 503-514.

Currer, C. (2009). Assessing Student Social Workers' Professional Suitability: Comparing University Procedures in England. British Journal of Social Work, 39(8), 1481-1498.

Dillon, J. (2007). The Conundrum of Balancing Widening Participation with the Selection of Suitable Students for Social Work Education. Social Work Education, 26(8), 827-841.

Furness, S., \& Gilligan, P. (2004). Fit for purpose: issues from practice placements, practice teaching and the assessment of students' practice. Social Work Education, 23(4), 465-479.

Gillis, H., \& Lewis, J. S. (2004). Addressing the issue of psychiatric disability in social work interns: The need for a problem solving framework. Journal of Social Work Education, 40(3), 391.

GlenMaye, L. F., \& Bolin, B. (2007). Students with psychiatric disabilities: An exploratory study of program practices. Journal of Social Work Education, 43(1), 117-131.

Hunt, J., \& Eisenberg, D. (2010). Mental health problems and help-seeking behavior among college students. The Journal of Adolescent Health, 46(1), 3-10.

Kessler, R. C., Foster, C. L., Saunders, W. B., \& Stang, P. E. (1995). Social consequences of psychiatric disorders, I: Educational attainment. The American Journal of Psychiatry, 152(7), 1026.

Khawaja, N. G., \& Dempsey, J. (2007). Psychological Distress in International University Students: An Australian Study. Australian Journal of Guidance and Counselling, 17(1), 13-27.

Lafrance, J., \& Gray, E. (2004). Gate-keeping for professional social work practice. Social Work Education, 23(3), 325-340.

Lloyd, C., \& Waghorn, G. (2007). The Importance of Vocation in Recovery of Young People with Psychiatric Disabilities. British Journal of Occupational Therapy, 70(2), 50-59.

Mansbach-Kleinfeld, I., Sasson, R., Shvarts, S., \& Grinshpoon, A. (2007). What Education Means to People with Psychiatric Disabilities: A Content Analysis. American Journal of Psychiatric Rehabilitation, 10(4), 301-316.

Manthorpe, J., \& Stanley, N. (1999). Dilemmas in professional education: responding effectively to students with mental health problems. Journal of Interprofessional Care, 13(4), 355-365.

Martin, J., \& Oswin, F. (2007). Post-secondary education: Obstacles and opportunity for recovery, paper presented at the Mental Health Services Conference, Melbourne. 
McMichael, A. J., \& Hetzel, B. S. (1974). Patterns of help-seeking for mental illness among Australian university students: an epidemiological study. Social science \& medicine, 8(4), 197-206.

Megivern, D., Pellerito, S., \& Mowbray, C. (2003). Barriers to higher education for individuals with psychiatric disabilities. Psychiatric Rehabilitation Journal, 26(3), 217-231.

Mowbray, C. T., Collins, M. E., Bellamy, C. D., Megivern, D. A., Bybee, D., \& Szilvagi, S. (2005). Supported Education for Adults with Psychiatric Disabilities: An Innovation for Social Work and Psychosocial Rehabilitation Practice. Social Work, 50(1), 7-20. doi: 10.1176/appi.ps.51.6.774.2000-15883-00410.1176/appi.ps.51.6.774

Olney, M. F., \& Brockelman, K. F. (2003). Out of the disability closet: strategic use of perception management by select university students with disabilities. Disability \& Society, 18(1), 35-50.

Owen, J., \& Rodolfa, E. (2009). Prevention through Connection: Creating a Campus Climate of Care. Planning for Higher Education, 37(2), 26-33.

Owen, J., Tao, K., \& Rodolfa, E. (2006). Distressed and Distressing Students: Creating a Campus Community of Care. In College Student Mental Health: Effective Services and Strategies Across Campus, eds. S. A. Benton and S. L. Benton, 15-34.. Washington, DC: National Association of Student Personnel Administrators.

Pearce, K., Rickwood, D., \& Beaton, S. (2003). Preliminary Evaluation of a University-based Suicide Intervention Project: Impact on Participants. Australian e-Journal for the Advancement of Mental Health, The, 2(1), 25-35.

Piper, F., \& MacDonald, B. (2008). 'Sometimes It's Harder to Speak Out Things': How First Year New Zealand Tertiary Students Use Informal Online Communication to Help Solve Significant Problems. Australian e-Journal for the Advancement of Mental Health, The, 7(3), [135]-[142].

Pooler, D. K., Clay Siebert, D., Faul, A. C., \& Huber, R. (2008). Personal History and Professional Impairment. Administration in Social Work, 32(2), 69-85.

Ridley, J., Stanley, N., Manthorpe, J., \& Harris, J. (2008). Disabled students and staff: disclosing disability. Community Care (1717), 32.

Ryan, M. L., Shochet, I. M., \& Stallman, H. M. (2010). Universal Online Interventions Might Engage Psychologically Distressed University Students Who Are Unlikely to Seek Formal Help. Advances in Mental Health, 9(1), 73-83.

Schwartz, V., \& Kay, J. (2009). The Crisis in College and University Mental Health. Psychiatric Times, 26(10), 32-32,34.

Shaddock, A. (2004). Academics' responses to the challenging behaviour of students with mental illness. JANZSSA(23), 53-77.

Shankar, J., Martin, J., \& McDonald, C. (2009). Emerging Areas of Practice for Mental Health Social Workers: Education and Employment. Australian Social Work, 62(1), 28-44.

Sin, C. H., \& Fong, J. (2009). The Impact of Regulatory Fitness Requirements on Disabled Social Work Students. British Journal of Social Work, 39(8), 1518-1539.

Stallman, H. (2008). Prevalence of psychological distress in university students: implications for service delivery. Australian Family Physician, 37(8), 673-677. 
Stanley, N., Mallon, S., Bell, J., \& Manthorpe, J. (2010). Suicidal students' use of and attitudes to primary care support services. Primary Health Care Research \& Development, 11(4), 315-325.

Stanley, N., Manthorpe, J., \& White, M. (2007). Depression in the profession: Social workers' experiences and perceptions. British Journal of Social Work, 37(2), 281-298.

Stanley, N., Ridley, J., Manthorpe, J., Harris, J., \& Hurst, A. (2010). Disclosing Disability: Disabled Students and Practitioners in Social Work. Nursing and Teaching, Social Care Workforce Research Unit.

Stromwall, L. K. (2002). Is social work's door open to people recovering from psychiatric disabilities? Social work, 47(1), 75-83.

Toombs, M., \& Gorman, D. (2011). Mental Health and Indigenous University Students. Aboriginal and Islander Health Worker Journal, 35(4), 22-24.

Venville, A. (2010). Risky business: Mental illness, disclosure and the TAFE student. International Journal of Training Research, 8(2), 128-140.

Waghorn, G., Still, M., Chant, D., \& Whiteford, H. (2004). Specialised supported education for Australians with psychotic disorders. Australian Journal of Social Issues, 39(4), 443-458.

Weiner, E. (1996). An exploratory qualitative study of three university students with mental illness and the perceived role their families play in their university education. Psychiatric Rehabilitation Journal, 19(3), 77-80.

Wiener, E. (1999). The Meaning of Education for University Students with a Psychiatric Disability: A grounded Theory Analysis. Psychiatric Rehabilitation Journal, 22(4), 403-409.

Wolf, J., Coba, C., \& Cirella, M. (2001). Education as psychosocial rehabilitation: Supported education program partnerships with mental health and behavioral healthcare certificate programs. Psychiatric Rehabilitation Skills, 5(3), 455-476.

Wray, J., Gibson, H., \& Aspland, J. (2007). Research into Assessments and Decisions Relating to 'Fitness' in Training, Qualifying and Working within Teaching, Nursing and Social Work. Disability Rights Commission.

Zivin, K., Eisenberg, D., Gollust, S. E., \& Golberstein, E. (2009). Persistence of mental health problems and needs in a college student population. Journal of Affective Disorders, 117(3), 180-185.

Wingert, S., Higgitt, N. \& Ristock, J. (2005). Voices from the margins: understanding street youth in Winnepeg. Canadian Journal of Urban Research, vol 14 (1), 54-80.

\section{Biographical Notes}

Donna McAuliffe is an Associate Professor in the School of Human Services and Social Work at Griffith University. Her teaching and research interests lie in the area of professional ethics, and she is committed to ensuring that practitioners and employers understand their ethical responsibilities. Dr McAuliffe led the last review of the Australian Association of Social Workers review of the Code of Ethics that upholds principles of 
respect for persons, social justice and professional integrity. She has a strong studentcentered position on provision of quality tertiary education.

Dr Jennifer Boddy is a lecturer with Griffith University, Queensland. She has previously worked with the University of Newcastle as a lecturer, NSW Health as a counsellor, and with Centacare Children's Services as a case worker. She holds the values of social justice, human dignity and worth, and integrity at the forefront of her teaching and research. Dr Boddy has maintained an active role in social work practice, mentoring practitioners on scholarly endeavours. She has successfully produced high quality publications in health and welfare and she is currently working on several studies that explore the psychosocial affects of chronic illness, community capacity building, and advance care planning.

Dr Vanette McLennan has worked as a rehabilitation counsellor, including counselling and disability case management roles. Since obtaining her $\mathrm{PhD}$, she has been involved in projects looking at advance care planning, chronic illness and parenting, and encouraging rural/remote student placement and practice. She is experienced in qualitative research, including data collection, analysis and dissemination.

Victoria Stewart is an Associate Lecturer in the Graduate Certificate and Masters of Mental Health Practice programs in the School of Human Services and Social Work at Griffith University. As an Occupational Therapist, Vicky has worked in a number of areas of practice in Australia, U.K. and U.S.A. She has specialised in mental health and vocational rehabilitation over the last 15 years and has worked in Commonwealth and State Government agencies as well as in the private and non-government sector. Vicky is also responsible for convening field placements for mental health students and teaching case management skills to undergraduate students. 